\title{
Effect of Perturbation of Specific Folate Receptors during In Vitro Erythropoiesis
}

\author{
Asok C. Antony, Edward Bruno, Robert A. Briddell, John E. Brandt, Rama S. Verma, and Ronald Hoffman
}

Division of Hematology/Oncology, Department of Medicine, Indiana University School of Medicine, Indianapolis, Indiana 46223

\begin{abstract}
Although antisera to specific placental folate receptors inhibits the uptake of 5-methyltetrahydrofolate into cultured malignant human cells, little is known of the functional significance of folate receptors in normal human cells. Human bone marrow cells were therefore assayed for erythropoietic burst-forming units in the presence of an antihuman placental folate receptor serum and preimmune serum to determine the role of such a receptor in erythroid differentiation. When marrow cells were assayed in the presence of anti-receptor antiserum, there was (i) a threefold increase in erythropoietic burst formation and a twofold increase in the number of cells per erythroid burst; (ii) morphological evidence for nuclear/cytoplasmic dissociation of orthochromatic normoblasts composing erythroid bursts (megaloblastic erythropoiesis); (iii) intracellular folate deficiency with a $70 \%$ reduction of intracellular folate in antiserum treated cells as compared with control cells; and (iv) complete reversal of antiserum-induced changes on preincubation of antiserum with purified human placental folate receptor. These data support the conclusion that folate receptors on marrow cells provide an important function in the cellular uptake of folates during in vitro erythropoiesis. This process of folate uptake also appears to play a pivotal role in the differentiation and proliferation of erythroid progenitor cells.
\end{abstract}

\section{Introduction}

All human cells require folates intracellularly for enzyme reactions that are crucial to the synthesis of deoxyribonucleic acid (1). Recently, we established that specific, high affinity, externally-oriented, membrane-associated folate-binding proteins (FBPs) ${ }^{1}$ on the surface of malignant human nasopharyngeal carcinoma $(\mathrm{KB})$ cells act as specific transport proteins in the cellular uptake of folates (2). However, little is known about the existence or function of similar proteins in normal human cells.

Address all correspondence to Dr. A. C. Antony, Clinical Bldg., Rm. 379, Indiana University School of Medicine, Indianapolis, IN 46223.

Received for publication 12 January 1987 and in revised form 17 April 1987.

1. Abbreviations used in this paper: BFU-E, burst-forming unit-erythroid; FBP, folate-binding protein; IMDM, Iscove's modified Dulbecco's medium; KB, nasopharyngeal carcinoma; PFR, placental folate receptor; PteGlu, pteroylglutamate.

J. Clin. Invest.

(c) The American Society for Clinical Investigation, Inc. $0021-9738 / 87 / 12 / 1618 / 06 \$ 2.00$

Volume 80, December 1987, 1618-1623
Earlier, we identified by indirect immunofluorescence studies that immunologically similar proteins to human placental folate receptors (PFR) were present on circulating human erythrocytes (3). Since erythrocytes have a 30 -fold higher intracellular folate concentration than serum (1), we suggested that this gradient could be mediated by specific folate transport proteins (3). Although subsequent investigations identified that human erythrocyte membranes (4), ghosts and intact cells (5), contained FBPs that had similar characteristics of folate binding as KB cell FBPs (2), the magnitude of folate uptake in circulating erythrocytes (in contrast to $\mathrm{KB}$ cells) was much lower and not consistent with a physiologically significant specific FBP-mediated uptake system (5a). Furthermore, the majority of erythrocyte FBPs identified by a specific radioimmunoassay to PFR (6) were nonfunctional in that they did not bind radiolabeled folate (5a). These studies suggested that the higher intracellular folate content in the erythrocyte was probably achieved at an earlier stage in development. Using in vitro hematopoietic progenitor cell assays, we asked the following questions: $(i)$ Is the development of erythroid progenitor and precursor cells dependent on the functional integrity of specific folate receptors? and (ii) Can perturbation of specific folate receptors on these cells lead to qualitative and/or quantitative changes consistent with folate deficiency? Our studies appear to support the conclusion that specific folate receptors mediate folate uptake in normal human marrow cells in vitro.

\section{Methods}

Iscove's modified Dulbecco's medium (IMDM) containing $4 \mathrm{mg}$ folic acid per liter, and preservative-free sodium heparin were obtained from Gibco, Grand Island, NY. Partially purified human urinary erythropoietin ( $72 \mathrm{U} / \mathrm{mg}$ of protein) was obtained from Toyobo Co., New York, NY. Fetal calf serum and rabbit preimmune serum were purchased from HyClone Laboratories, Inc., Logan, UT, whereas ${ }^{125} \mathrm{I}$ labeled folic acid (an iodinated histamine derivative of folic acid, purity $98 \%$, with a specific activity of $2,200 \mathrm{Ci} / \mathrm{mmol}$ ) was obtained from DuPont Co., Diagnostic \& BioResearch Systems, Wilmington, DE, and New England Nuclear, Boston, MA. Folic acid (99\% pure), $\beta$-lactoglobulin, and monobasic and dibasic potassium phosphate were obtained from Sigma Chemical Co., St. Louis, MO. Norit charcoal, methylcellulose, and Wright Giemsa "Accustain" were obtained from Fisher Scientific Co., Fairlawn, NJ. Ficoll-Hypaque was purchased from Pharmacia Fine Chemicals, Piscataway, NJ, whereas 2-mercaptoethanol was obtained from Eastman Kodak Co., Rochester, NY.

Preparation of antifolate receptor antibody. Human PFR was purified to apparent homogeneity based on its migration as a single stained band during sodium dodecyl sulfate-polyacrylamide gel electrophoresis (3). Rabbit antihuman PFR serum was raised by injecting the purified PFR (emulsified with Freund's adjuvant) into a New Zealand White rabbit, as previously described $(3,7)$.

Cultures of erythroid progenitor cells in vitro. Human bone marrow cells were aspirated from the posterior iliac crest of hematologically normal volunteers according to guidelines established by the Human Investigations Committee of Indiana University School of Medicine. The marrow aspirates were diluted 1:1 with IMDM containing sodium 
heparin at $20 \mathrm{U} / \mathrm{ml}$. This mixture was layered over an equal volume of Ficoll-Hypaque (specific gravity of $1.077 \mathrm{~g} / \mathrm{cm}^{3}$ ) and density centrifugation performed at $500 \mathrm{~g}$ for $25 \mathrm{~min}$ at $4^{\circ} \mathrm{C}$ in a centrifuge (model TJ-6R; Beckman Instruments, Fullerton, CA). The interface mononuclear low density cell layer was collected, washed with 20 vol of IMDM, and cells were enumerated before use in culture. Assays for the human burst-forming unit-erythroid (BFU-E) were carried out according to the method of Fauser and Messner (8). In brief, $1 \times 10^{5}$ low density bone marrow mononuclear cells were suspended in $35-\mathrm{mm}$ standard tissue culture dishes, containing a $1-\mathrm{ml}$ mixture of IMDM, $1.1 \%$ methylcellulose, $30 \%$ fetal bovine serum, $5 \times 10^{-5} \mathrm{M}$ 2-mercaptoethanol, $1 \mathrm{U}$ of erythropoietin, and $10 \%$ of either preimmune serum or varying dilutions of antihuman PFR antiserum. All sera were routinely filtered with $0.22 \mu \mathrm{m}$ Millex-GV filters (Millipore/Continental Water Systems, Bedford, MA) before addition to culture. To test for the specificity of antiserum, $800 \mu \mathrm{l}$ antihuman PFR antiserum or preimmune serum was incubated with $2 \mu \mathrm{g}$ purified human PFR (stock solution of $1 \mathrm{mg} / \mathrm{ml}$ protein in $0.1 \mathrm{M}$ potassium phosphate, $\mathrm{pH} 7.5$, containing $1 \%$ Triton $\mathrm{X}-100$ and $0.15 \mathrm{M} \mathrm{NaCl}$ ) for $2 \mathrm{~h}$ at $37^{\circ} \mathrm{C}$ before addition to the erythroid progenitor cell assay system.

The culture plates were incubated at $37^{\circ} \mathrm{C}$ in a light-protected, humidified atmosphere of $5 \% \mathrm{CO}_{2}$ in air. BFU-E were scored after $14 \mathrm{~d}$ using standard criteria $(8,9)$. To determine the number of cells per erythroid colony, plates containing enumerated numbers of erythroid bursts were harvested into sterile PBS $(10 \mathrm{mM}$ potassium phosphate, pH 7.5, containing $150 \mathrm{mM} \mathrm{NaCl}$ ) and the cells sedimented at $1,000 \mathrm{~g}$ for $10 \mathrm{~min}$ at $22^{\circ} \mathrm{C}$. The resulting supernatant was aspirated, discarded, and the sedimented cells were washed with $50 \mathrm{vol}$ of PBS for three additional centrifuge-wash cycles, as described above. They were finally resuspended in $0.5 \mathrm{ml}$ PBS and total erythroid cell counts were determined manually with a hemocytometer. Based on the number of cells derived from a known number of erythroid bursts per plate, the approximate number of erythroid cells per erythroid burst was determined. Erythroid colonies were also directly plucked from methylcellulose cultures with a sterile tapered pasteur pipette under direct microscopic visualization, and cells $(\sim 10,000)$ were resuspended in $100 \mu \mathrm{l}$ PBS and transferred to slides using a centrifuge (Shandon Cytocentrifuge II; Shandon Southern Instruments Inc., Sewickley, PA) at 750 $\mathrm{rpm}$ for $5 \mathrm{~min}$. After drying and fixation with methanol, the stained cells were observed for morphological changes. Orthochromatic normoblast cell sizing was performed using a digital filar eyepiece (Los Angeles Scientific Instrument Co., Los Angeles, CA) adaptable to a standard light microscope. Also, the number of nuclei per cell was determined in each group of cells described above.

Assay for endogenous intracellular folate. Erythroid bursts were plucked from culture plates containing cells incubated with either rabbit preimmune or antihuman PFR antiserum. The percentage of erythroid cells in these bursts were $>98 \%$. Cells from 14 antisera and 18 preimmune sera-treated plates were separately pooled, washed with 100 vol of PBS for two centrifuge-wash cycles as described above, resuspended in $5 \mathrm{ml} \mathrm{PBS}$, and the number of cells $/ \mathrm{ml}$ determined. The cells were subsequently frozen at $-70^{\circ} \mathrm{C}$ in dry ice-acetone and thawed at $22^{\circ} \mathrm{C}$ in a water bath for two cycles to lyse the cells. The mixture was centrifuged at $30,000 \mathrm{~g}$ for $30 \mathrm{~min}$ at $4^{\circ} \mathrm{C}$ in a centrifuge (model J-21; Beckman Instruments), and the supernatant containing released intracellular material was filtered through $0.22 \mu \mathrm{m}$ Millex-GV filters to retain particulate material. The filtrate was subsequently assayed for folate content, as previously described $(7,10,11)$. The standard curve for the radioisotope dilution assay was based on the ability of known concentrations of unlabeled folic acid (pteroylglutamate [PteGlu]) to competitively inhibit the binding of ${ }^{125}$ I-labeled folic acid (histamine derivative) to bovine FBP (present as a contaminant in $\beta$-lactoglobulin). Briefly, a final reaction volume of $1 \mathrm{ml}$ contained 160 $\mu \mathrm{mol}$ borate-KOH, $\mathrm{pH} 9.5,2 \mu \mathrm{mol}$ dithiothreitol, $10 \mu \mathrm{mol} 2$-mercaptoethanol, $5 \mathrm{fmol}{ }^{125} \mathrm{I}$-labeled folic acid (histamine derivative), and increasing concentrations of unlabeled PteGlu $(0.05-5 \mathrm{pmol})$ or the sample to be measured for endogenous folate. The mixtures were boiled at $100^{\circ} \mathrm{C}$ and cooled at $22^{\circ} \mathrm{C}$ and $\beta$-lactoglobulin $(4 \mu \mathrm{g})$ was added to each tube (Eppendorf Microfuge; Brinkmann Instruments Inc., Westbury, NY). After incubation for $30 \mathrm{~min}$ at $22^{\circ} \mathrm{C}, 0.8 \mathrm{mg}$ dextran-coated charcoal was added and the mixtures were incubated another $10 \mathrm{~min}$ at $22^{\circ} \mathrm{C}$. The samples were subsequently centrifuged in a centrifuge (model 59A Micro-Centrifuge, Fisher Scientific Co.) for 2 min at top speed, and $0.5 \mathrm{ml}$ of each supernatant (containing radiolabeled folate-bound FBP) was counted for radioactivity. The radioactivity of the supernatant in the sample was directly compared with that of the standard curve obtained with PteGlu. Under the conditions of the assay, both PteGlu as well as 5-methyltetrahydrofolate bind bovine FBPs with comparably high affinity (10). This assay however fails to detect other folate forms (such as 5-formyltetrahydrofolate) that have lower affinity and consequently lower ability to displace ${ }^{125}$ I-labeled folic acid (histamine derivative) from bovine FBP relative to PteGlu. The assay had an upper limit of sensitivity of $100 \mathrm{fmol}$ and a lower limit of sensitivity of 5 pmol PteGlu. Each sample for folate analysis was assayed in triplicate at various dilutions, and the concentration of folate in the unknown sample that was well within the standard curve was determined. Based on the number of cells in each sample (treated with preimmune and immune serum) and the results from the assay for endogenous folate (released from these cells), the concentration of intracellular folate per cell was determined.

Statistical analysis. Each of the experiments described above were carried out on three or more occasions using bone marrow cells from different human subjects. The results of cloning efficiency, and morphology of erythroid progenitor cells in the presence of rabbit preimmune and immune serum was quantitatively and qualitatively comparable with $<10 \%$ variation. The data for BFU-E-derived colonies is expressed as the mean \pm SD from quadruplicate values of colony assays, and levels of statistical significance were determined using the student's $t$ test. The values for endogenous folate performed in triplicate in preimmune and immune serum-treated cells are expressed as the mean \pm SD from cells of one volunteer. In two subsequent experiments with bone marrow cells from different volunteers, the values for endogenous folate did not significantly differ ( $<10 \%$ variation) from one another in immune and preimmune serum-treated cells.

\section{Results}

Rabbit preimmune serum resulted in slight but insignificant augmentation of formation of erythroid bursts in vitro compared with control cells grown in the absence of rabbit serum. Incubation of cells with increasing concentrations of antihuman PFR antiserum, however, resulted in a progressive increase in the number of erythroid bursts over concomitant controls assayed in the presence of preimmune serum alone (Fig. 1). With complete replacement of preimmune serum by antihuman PFR antiserum, there was a 3.9-fold greater number of BFU-E-derived colonies per plate as compared with controls containing preimmune serum alone. Also, the erythropoietic bursts developed in the presence of antihuman PFR antiserum were larger and contained $\sim$ twofold greater number of cells $(6,100 \pm 300$ cells/BFU-E-derived colony) as compared with controls developed in the presence of preimmune serum $(3,450 \pm 150$ cells/BFU-E-derived colony).

Analysis of Wright-Giemsa stained cells from BFU-E-derived colonies assayed in the presence of antihuman PFR antiserum, but not in preimmune serum, revealed findings that were consistent with morphological changes associated with megaloblastic erythropoiesis (Fig. 2 top, middle, bottom). This was best appreciated in orthochromatic normoblasts that contained fine nuclear chromatin that was more characteristic of nuclei from proerythroblasts and early normoblasts (Fig. 2 bottom); also, many such cells contained evidence of dyseryth- 


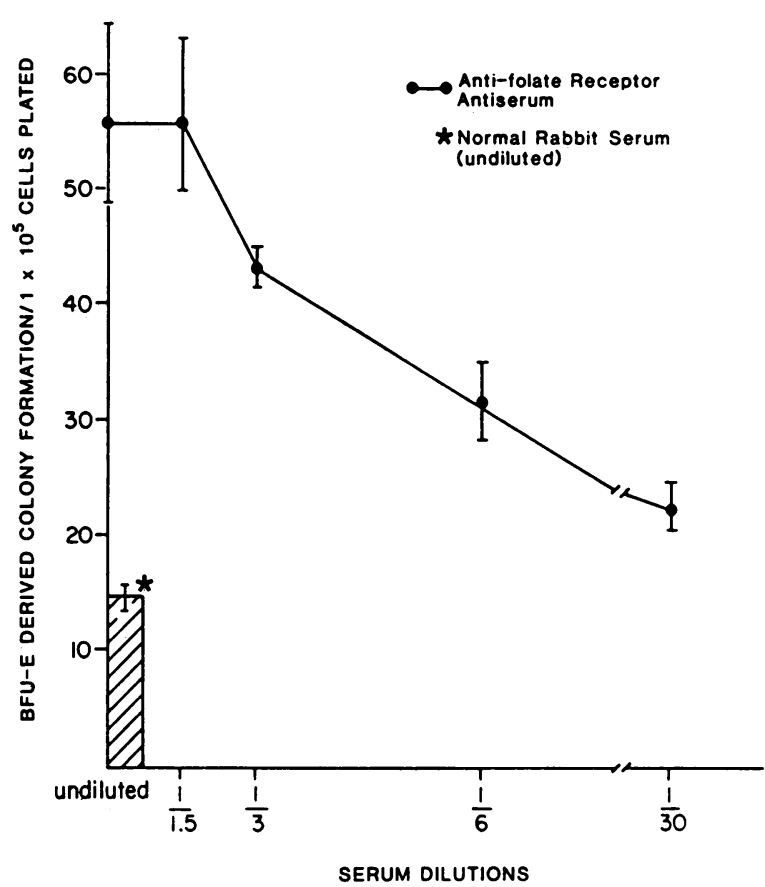

Figure 1. Effect of various dilutions of antiPFR antiserum on BFU-E-derived colony formation. Each point represents the mean $\pm \mathrm{SD}$ of assays performed in quadruplicate. Similar results were obtained in three additional studies.

ropoiesis with two or more nuclei per cell that were joined by fine internuclear bridging material (Fig. 2 middle). Also, there was marked retardation of nuclear maturity and pyknosis in antiserum-treated cells; these morphological findings are consistent with functional nuclear-cytoplasmic asynchrony, which is the hallmark of megaloblastic erythropoiesis (1).

To be certain if the effects of the antihuman PFR antiserum on in vitro erythropoiesis were specifically due to antibody-mediated perturbation of a protein immunologically similar to the PFR, immune serum was preincubated with excess purified PFR before incubation with marrow cells. Under these circumstances, cultures containing PFR mixed with immune serum had no evidence of increased cloning efficiency and were similar to control cells grown in preimmune serum both in the absence or presence of purified PFR (Table I). These results indicated that the unique effect of antihuman PFR antiserum alone was mediated by specific antibodies that bound to folate receptors on marrow cells that were immunologically cross-reactive with human PFR.

To avoid any observer bias in the morphological evaluation of normoblasts in cytospin preparations of antiserum and preimmune serum-treated cells, we introduced quantitative measurements of dyserythropoiesis. As shown in Table I, antihuman PFR antiserum-treated cells had a significantly $(P$ $<0.001)$ greater $(a)$ cell diameter, $(b)$ percent of cells having more than one nucleus, and $(c)$ number of nuclei per cell when compared with control cultures or rabbit preimmune serumtreated cultures, or antihuman PFR antiserum plus PFRtreated assays. Also, smears from all experimental groups (Table I) were observed and scored by three other certified hematopathologists who were "blinded" to the study. Both they and two of the authors (Antony and Hoffman) could reproducibly distinguish morphological characteristics of meg- aloblastic erythropoiesis in antiserum-treated vs. preimmune serum-treated cells.

To determine if perturbation of folate receptors on BFU-E by specific antihuman PFR antiserum resulted in intracellular folate deficiency (thereby accounting for megaloblastic changes), the intracellular folate content of erythroid cells composing the resultant bursts was determined. Bursts from plates developed in the presence of preimmune serum and antiserum were harvested, washed, and lysed, and the released intracellular folates were quantitated by a radioisotope dilution assay for endogenous folate. Preimmune serum-treated cells contained $0.104 \mathrm{fmol}$ folate/cell ( $3 \mathrm{pmol} \pm 0.20 \mathrm{SD}$ per 2.8 $\times 10^{4}$ cells), whereas anti-human PFR antiserum-treated cells, $0.035 \mathrm{fmol}$ folate/cell $\left(3.8 \mathrm{pmol} \pm 0.15 \mathrm{SD}\right.$ per $1.1 \times 10^{5}$ cells); thus, there was $67 \%$ less intracellular folate in antiserumtreated erythroid cells as compared with the intracellular folate content in cells incubated with preimmune serum.

Taken together, these studies strongly suggest that specific folate receptors play a major functional role in the accumulation of folate in erythroid progenitor cells in vitro.

\section{Discussion}

Circulating human erythrocytes are unique among human cells in that they have a single external plasma membrane without any intracellular organelles. The fact that these cells contain a 30-fold higher intracellular folate content as compared with that in serum has remained unexplained. The major form of serum folate is 5-methyltetrahydrofolate (monoglutamate), whereas intracellular folates are predominantly polyglutamated (12). The enzyme responsible for polyglutamation of folate, PteGlu synthetase, is however absent in mature cells (13). This suggests that the existing folate in mature cells was taken up as 5-methyltetrahydrofolate and subsequently polyglutamated in (immature) erythroid precursors within the bone marrow. However, the component(s) of a specific folate transport system in erythroid progenitors has not been identified.

During studies with high affinity, specific FBPs isolated from human placental membranes, we raised rabbit antiserum to the purified FBPs and identified the presence of immunologically cross-reactive moieties on mature human erythrocytes (3). Subsequent ligand binding studies with ${ }^{3} \mathrm{H}$ - and ${ }^{14} \mathrm{C}$ labeled folates did not detect significant specific radioligand binding to isolated erythrocyte membranes. With the recent synthesis of a stable radioiodinated histamine derivative of folic acid with a specific activity that was 50 -fold higher than previously available radiolabeled folates, as well as the development of a sensitive and specific radioimmunoassay for placental folate receptors and related high affinity specific FBPs (6), it was possible to extend earlier studies of FBPs on intact erythrocytes. We found $(4,5)$ that FBPs from purified membranes of circulating human erythrocytes possessed similar biochemical characteristics with respect to ligand binding, antigenic identities, molecular weights, external orientation, and hydrophobicity as physiological $\mathrm{KB}$ cell folate receptors (2, 11). However, the number of functional FBPs that participated in the binding and internalization of folates in erythrocytes was $<1 \%$ of the total number of immunoreactive FBPs per cell. Furthermore, folate uptake in circulating erythrocytes was four to six orders of magnitude less than that identified in $\mathrm{KB}$ cells. Taken together, these findings suggested that the 

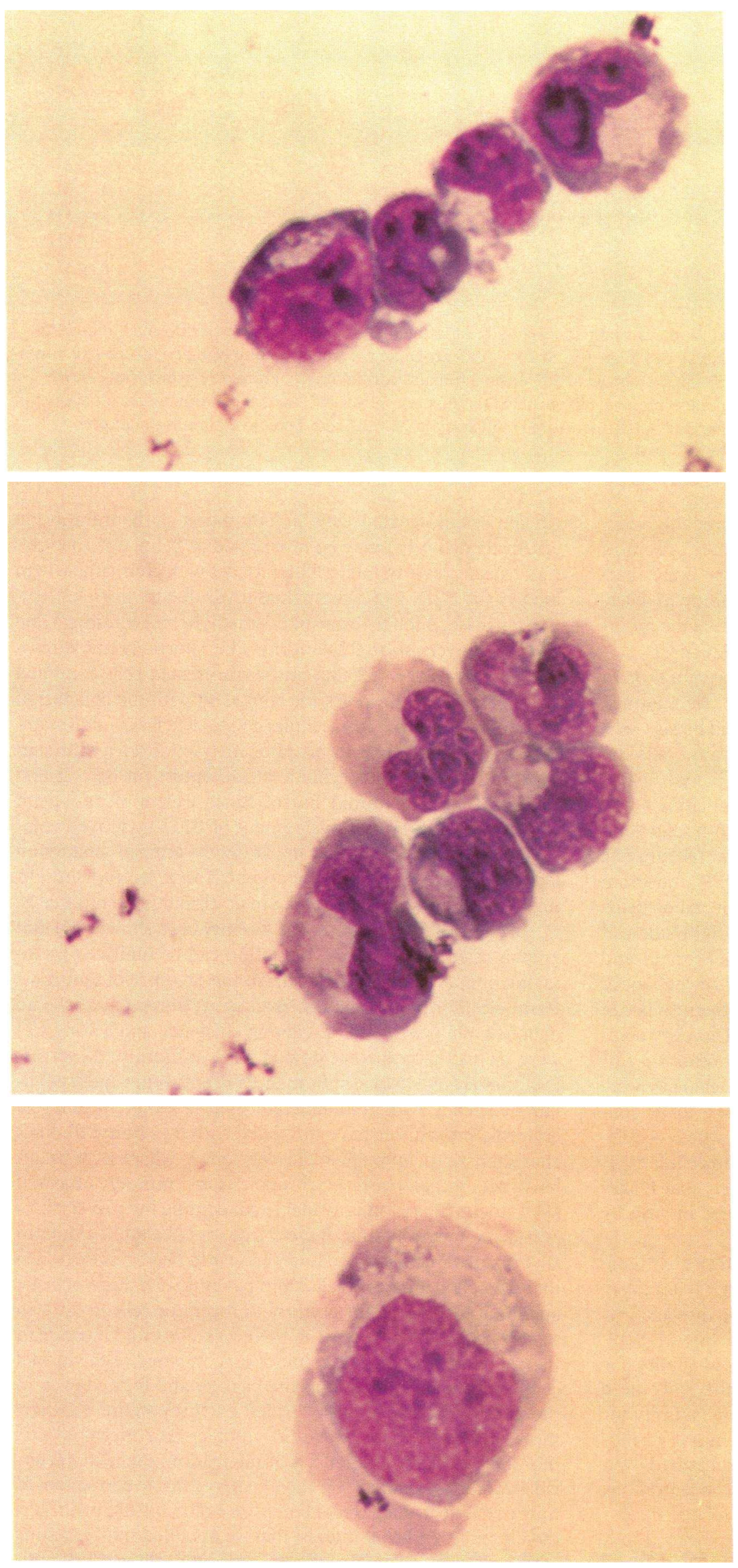

Figure 2. Alteration of erythroid burst morphology in the presence of $(t o p)$ preimmune serum $(\times 400)$ and (middle) antihuman PFR antiserum $(\times 400)$. (bottom) Higher magnifcation $(\times 1,000)$ of a megaloblastic orthochromatic normoblast from an erythroid burst developed in the presence of antihuman PFR antisera. 


\begin{tabular}{|c|c|c|c|c|}
\hline Addition to culture & $\begin{array}{l}\text { BFU-E-derived colony } \\
\text { formation } / 1 \times 10^{5} \\
\text { cells plated }\end{array}$ & $\begin{array}{l}\text { Normoblast cell } \\
\text { diameter }{ }^{*}\end{array}$ & $\begin{array}{l}\text { Normoblasts having } \\
>1 \text { nucleus }^{8}\end{array}$ & $\begin{array}{l}\text { Mean number of } \\
\text { nuclei/cell" }\end{array}$ \\
\hline & & $\mu m$ & $\%$ & \\
\hline None & $39.6 \pm 19.4$ & $8.4 \pm 0.4$ & 5 & $1.3 \pm 0.6$ \\
\hline Normal rabbit serum & $43.8 \pm 20.5$ & $9.4 \pm 0.3^{\pi}$ & 12 & $1.4 \pm 0.8$ \\
\hline Antifolate receptor antiserum & $101.2 \pm 47.5^{* *}$ & $13.2 \pm 0.4^{* *}$ & 47 & $1.8 \pm 0.8^{* *}$ \\
\hline Normal rabbit serum plus purified folate receptor & $34.6 \pm 10.8$ & $8.0 \pm 0.2$ & 2 & $1.3 \pm 0.8$ \\
\hline Antifolate receptor antiserum plus purified folate receptor & $44.0 \pm 13.3$ & $9.0 \pm 0.3$ & 13 & $1.2 \pm 0.5$ \\
\hline
\end{tabular}

* Each value represents the mean $\pm \mathrm{SD}$ of assays pooled from eight individual studies. In individual studies, assays were performed in quadruplicate. ${ }^{\ddagger}$ Each point represents the mean \pm SD of measured cell diameters of 200 orthochromatic normoblasts composing erythropoietic bursts in individual treatment groups. ${ }^{\S}$ Each point represents the percentage of 200 orthochromatic normoblasts composing erythropoietic bursts having $>1$ nucleus in each treatment group. "Each point represents the mean \pm SD number of nuclei per 200 orthochromatic normoblasts composing the erythropoietic bursts in each treatment group. " $P<0.05$ compared with assays to which there were no additions to culture.

** $P<0.001$ compared with all other experimental groups.

existing FBPs in circulating erythrocytes were probably vestigal remnants of a prior functional folate transport system in actively dividing erythroid precursors within the bone marrow. ${ }^{2}$ With this background, we attempted this study to determine if specific FBPs were functionally important in the proliferation and differentiation of erythroid progenitor cells.

With the advent of methods to specifically assay for human bone marrow erythroid progenitor cells in vitro, we reasoned that the FBPs on the surface of primitive erythroid lineage cells could be perturbed by antihuman PFR antiserum. This hypothesis was based on our earlier studies $(4,5,5 a)$, which showed $(i)$ cross-reactive material to PFR on circulating erythrocytes; (ii) immunoprecipitation of radioligand-bound solubilized erythrocyte FBP with antihuman PFR antiserum (4); and (iii) the demonstration that antihuman PFR antiserum could inhibit the binding and internalization of radiolabeled folate in circulating erythrocytes and sealed-right-side-out ghosts (5). The results from the present studies (Table I and Fig. 1) suggested that antihuman PFR antiserum enhanced BFU-E cloning efficiency as well as increasing the number of cells comprising individual erythroid bursts. The cells comprising the bursts were also megaloblastic by morphologic criteria (Fig. 2 and Table I). Significantly, these changes were associated with a marked reduction of intracellular folate content in antihuman PFR antiserum-treated cells, where $\sim$ onethird the amount of folate was accumulated intracellularly as compared with control cells. Therefore, it is likely that folatedeficient megaloblastic erythropoiesis was induced in vitro by antihuman PFR antiserum.

It is important to emphasize that the method to quantitate endogenous folate has definite limitations in that it relies solely on the ability of (released) intracellular folates to displace ${ }^{125}$ Ilabeled folic acid (histamine derivative) from bovine FBP. Since various folates differ significantly in their affinity for $\operatorname{FBPs}(3,7,10)$, it follows that the assay will identify only those folates (like 5-methyltetrahydrofolate) having high affinity for FBPs. Conversely, other folates (e.g., 5-formyltetrahydrofolate) having lower affinity for FBPs will not be measured even if they were present in significantly increased concentrations intracellularly. Moreover, since the forms of folates in erythroid precursor cells during in vitro erythropoiesis is not known, a decrease in measured endogenous intracellular folate (in antiserum-treated cells as compared with preimmune serum-treated cells) may be interpreted as being due to either (i) a true decrease in total cellular folates with comparable high affinity for FBPs like 5-methyltetrahydrofolate, or (ii) a relative decrease in folate forms like 5-methyltetrahydrofolate due to their conversion to folate forms like 5-formyltetrahydrofolate. However, the fact that antiserum-treated cells exhibited megaloblastic erythropoiesis is consistent with the conclusion that there was a true intracellular folate deficiency of 5-methyltetrahydrofolate-like forms after interaction of antihuman PFR antibodies with specific folate receptors on BFU-E and BFU-E-derived erythroid bursts. Since excess of antiserum was present during the development of BFU-E-derived colonies in vitro, we suggest that the antibody-antigen interaction led to a perturbation of the function of folate receptors resulting in inhibition of folate uptake in erythroid progenitor cells.

In contrast to our data, it has recently been shown (14) that growth of erythroid colony formation can be inhibited by assaying human bone marrow cells in the presence of antitransferrin receptor monoclonal antibodies. At present, we have no data to explain why BFU-E cloning efficiency and colony size were increased by the antihuman PFR antiserum. Nevertheless, these results with antihuman PFR antiserum-induced folate deficiency with resultant increased cloning efficiency of erythroid progenitors have correlated with the clinical findings characteristic of human folate deficiency, where hypercellularity with megaloblastic erythropoiesis is commonly observed (1). Little information is available concerning in vitro erythropoiesis in megaloblastic anemia due to cobalamin (vitamin $B_{12}$ ) or folate deficiency. However, it has been reported (15) that when bone marrow cells from patients with megaloblastic anemia were assayed for erythroid progenitor cells in vitro in the presence of erythropoietin, there was a fourfold increase in the number of erythroid colonies as compared with normal cells. Also, such colonies appeared earlier and formed even in the absence of exogenously added erythropoietin. Furthermore, although these erythroid colonies had megaloblastic morphologic features after $3 \mathrm{~d}$ of incubation, these characteristics were not evident by day 7 suggesting a correction of nutritional deficiency under conditions of in vitro growth. It is therefore of significant interest that we obtained similar results with cells assayed in the presence of antihuman PFR anti- 
serum (two- to threefold increase in erythroid bursts, twofold increase in cells per erythroid burst, megaloblastic features) as compared with cells grown in preimmune serum. Therefore, we hypothesize that in addition to mediating folate uptake in erythroid progenitors, interaction of antifolate receptor antibodies with folate receptors may result in augmentation of cell proliferation. The in vitro experimental model of intracellular folate deficiency as induced by perturbation of folate receptors with antihuman PFR antiserum may be used to address fundamental questions pertaining to the metabolism of folate receptors in erythroid progenitor cells at the biochemical and molecular level. Our recent studies with $\mathrm{KB}$ cells appear to indicate profound changes in intracellular folate and folate receptor metabolism as a consequence of altering the folate content in the growth media of these cells (16); therefore, it is possible that an analogous process may occur with erythroid progenitor cells in vitro.

One cautionary note should be considered when interpreting this data. We have presumed that the primary effects of the antihuman PFR antisera were directed against erythroid progenitor cells. Since it is likely that all marrow cells express similar proteins and the marrow cells assayed were relatively heterogeneous, an alternative explanation for our findings might involve the additional perturbation of folate receptors on marrow accessory cell populations that influence erythropoiesis. The effect of the antireceptor antisera on enriched populations of marrow cells will be pursued to explore these possibilities. Preliminary studies appear to suggest that cells comprising CFU-granulocyte-macrophage-derived colonies assayed in the presence of antihuman PFR antisera also exhibit features characteristic of megaloblastic hematopoiesis such as neutrophil hypersegmentation.

In summary, the findings that antihuman PFR antiserum mediates the induction of megaloblastic erythropoiesis in vitro provides strong evidences for a functional role of folate receptors in normal erythropoiesis.

\section{Acknowledgments}

We acknowledge the expert secretarial assistance of Shirley Duke and Stephanie Moore during the preparation of this manuscript.

This work was supported by grant R01 HD-20889 (to Dr. Antony) from the National Institutes of Health.

\section{References}

1. Wintrobe, M. M., G. R. Lee, D. R. Boggs, T. C. Bithell, J. Foerster, J. W. Athens, and J. N. Lukens. 1981. Clinical Hematology. Lea and Febiger, Philadelphia. 136-170, 559-604.

2. Antony, A. C., M. A. Kane, R. M. Portillo, P. C. Elwood, and J. F. Kolhouse. 1985. Studies of the role of a particulate folate-binding protein in the uptake of 5-methyltetrahydrofolate by cultured human KB cells. J. Biol. Chem. 260:14911-14917.

3. Antony, A. C., C. S. Utley, K. C. Van Horne, and J. F. Kolhouse. 1981. Isolation and characterization of a folate receptor from human placenta. J. Biol. Chem. 256:9684-9692.

4. Antony, A. C., R. S. Kincade, A. K. Gupta, and J. A. LaRosa. 1985. Characterization of a specific and non-specific mechanism for folate transport into mature human erythrocyte ghosts. Blood. 66:53. (Abstr.)

5. Antony, A. C., R. S. Kincade, and S. R. Krishnan. 1986. Evidence for dual mechanisms for folate uptake in human erythrocytes and malignant KB cells. Clin. Res. 34:450. (Abstr.)

5a. Antony, A. C., R. S. Kincade, R. S. Verma, S. R. Krishnan. 1987. Identification of high affinity folate binding proteins in human erythrocyte membranes. J. Clin. Invest. 80:711-723.

6. Antony, A. C., R. S. Verma, and R. S. Kincade. 1987. Development of a specific radioimmunoassay for placental folate receptors and related high affinity folate binding proteins in human tissues. Anal. Biochem. 162:224-235.

7. Antony, A. C., C. S. Utley, P. D. Marcell, and J. F. Kolhouse. 1982. Isolation, characterization and comparison of the solubilized particulate and soluble folate binding proteins from human milk. $J$. Biol. Chem. 257:10081-10089.

8. Fauser, A. A., and H. A. Messner. 1978. Granuloerythropoietic colonies in human bone marrow, peripheral blood and cord blood. Blood. 52:1243-1248.

9. Porter, P. N., and M. Ogawa. 1982. Characterization of human erythroid burst-promoting activity derived from bone marrow conditioned media. Blood. 59:1207-1212.

10. Waxman, S., and C. Schreiber. 1980. Determination of folate by use of radioactive folate and binding proteins. Methods Enzymol. 66:468-483.

11. Kane, M. A., P. C. Elwood, R. M. Portillo, A. C. Antony, and J. F. Kolhouse. 1986. The interrelationship of the soluble and membrane-associated folate binding protein in human KB cells. J. Biol. Chem. 261:15625-15631.

12. Beck, W. S. 1983. Metabolic aspects of vitamin $B_{12}$ and folic acid. In Hematology. W. J. Williams, E. Beutler, A. J. Erslev, R. W. Rundles, and M. A. Lichtman, editors. McGraw Hill Book Co., New York. 311-331.

13. Rowe, P. B. 1983. Inherited disorders of folate metabolism. In Metabolic Basis of Inherited Disease. J. B. Stanbury, J. B. Wyngaarden, D. S. Fredrickson, J. L. Goldstein, and M. S. Brown, editors. McGraw Hill Book Co., New York. 498-521.

14. Shannon, K. M., J. W. Larrick, S. A. Fulcher, K. B. Burck, J. Pacely, J. C. Davis, and D. B. Ring. 1986. Selective inhibition of the growth of human erythroid bursts by monoclonal antibodies against transferrin or the transferrin receptor. Blood. 67:1631-1638.

15. Hoffman, R., E. D. Zanjani, R. Zalusky, and L. R. Wasserman. 1975. Erythroid colony growth in disorders of erythropoiesis. Blood. 46:1023. (Abstr.)

16. Kane, M. A., R. M. Portillo, P. C. Elwood, A. C. Antony, and J. F. Kolhouse. 1986. The influence of extracellular folate concentration on methotrexate uptake by human KB cells. Partial characterization of a methotrexate binding protein. J. Biol. Chem. 261:44-49. 